\title{
Tables and boxes
}

\section{TABLES}

3.1 Summary description of different management terms

3A.1 Management terms in the academic literature

5.1 Means, standard deviations and intercorrelations of the research variables

5.2 Results of moderated mediation analysis

12.1 Examples of positive and negative outcomes of the four different aspects/types of learning organization for the three stakeholders

15.1 Company characteristics

15.2 Distribution of interview partners in the different waves of data collection

15A.1 Characteristics of interviewed persons (to guarantee anonymity, categories have been formed)

17.1 Where, by whom and how were the translations carried out?

19.1 The theoretical framework

\section{BOXES}

10.1 Adoption and adaptation of management panaceas in Red Box Company

20.1 Eight principles for excellence

20.2 The ingredients of successful change

25.1 Global complexity: how well do you know the world? A game of not-so-trivial cross-cultural pursuit 